\title{
1. Integrative perspectives on service, innovation and experience research
}

\section{Ada Scupola and Lars Fuglsang}

\section{INTRODUCTION}

The aim of the book is to develop and discuss integrative approaches to the fields of innovation, service and experience research. Professor Jon Sundbo (Sundbo, 1997, 2000; Sundbo and Sørensen, 2013) has been a pioneer in the fields of service innovation research and experience economy both in Denmark and at European level and has prepared the ground together with other researchers (e.g., Toivonen, Gallouj and Fuglsang) for the development of these fields. However, these research fields have been mostly developed in an autonomous way and no research trying to connect them has been undertaken so far. The aim of this book is to establish a link between these apparently different, but somehow related, research fields. The book is a tribute to Professor Jon Sundbo and therefore the book authors all have in common the fact that they have contributed over the years to form and shape the fields of service, innovation and experience economy at European level in addition to collaborating in one way or another with Professor Sundbo.

\section{SETTING THE STAGE}

For a long time, innovation research has focused mostly on manufacturing industries. From the 1990s, literature on innovation in services emerged to investigate whether and how innovation in services takes place and its place in the economy. Recently, there has been convergence between manufacturing industries and service industries, as many manufacturing firms are repositioning themselves as service firms (or marketing their products as service solutions) and service firms are standardizing their service offerings, thus resembling goods. This phenomenon has been called the 'servitization' of manufacturing (e.g., Baines et al., 2009). In services, standardization may lead to less flexibility in relation to individual users, 
yet new platform-based services make it possible both to standardize service offers, thus reaching more customers, and to allow users to coproduce services. In addition, consumers are becoming more sophisticated and expect more from both goods and services. They look for quality but also for experiences that are memorable events (Pine and Gilmore, 2017). Therefore, a new field of research investigating experiences, and how experiences can be triggered as an economic activity, has emerged in the past years - investigating experiences both as an industry per se and as a further development of service offerings.

It is well known that Pine and Gilmore (1999) have laid the foundations for what is called the experience economy, a new economic activity with its own logic - the experience logic. According to Pine and Gilmore, this new economic logic positions experiences as the core product/service and such experiences are as different from services as services are from goods. In addition, they argue that many more companies are offering experiences as part of their business - often becoming an essential part of core service offerings. In addition to this, the advancement in information and communication technologies (ICTs) has enabled and given rise to whole new types of entertainments such as online games, social media and virtual reality (Pine and Gilmore, 2017). Some of these provide core experiences themselves, such as online games; others can be core entertainments themselves or can be used as add-ons to core products/services, such as different types of Apps (ibid.).

However, companies whose core business may be service or goods production may also engage in staging experiences when they 'engage customers in a personal, memorable way' (Pine and Gilmore, 1998). In order to explain experiences as distinct economic offerings, Pine and Gilmore (2017) compare their characteristics with the main characteristics of services. They state that first, while services are delivered, experiences are staged, and companies should try to rethink the service delivery to ensure it becomes a lasting and memorable experience. Second, while services are often intangible operations transforming a reality of a customer - that is, services have little or no materiality as opposed to tangible goods - experiences are the memorable events in the mind of the customer. Third, while services are customized, developed for or co-created by individual persons (or companies in a business-to-business context), experiences are basically very personal and subjective. Finally, Pine and Gilmore (2017) argue that while service provision is made on customer demand, experiences usually become disclosed to the mind of the customer over a period of time.

Until now, innovation has been studied differently in these different economic sectors (manufacturing, services and experience) and theories have been developed for each sector. Researchers have discussed how 
innovation differs in services and manufacturing and whether it can be understood from one theory or requires different theories (e.g., Gallouj and Weinstein, 1997; Sundbo, 1997). The same discussion was repeated when researchers began to study innovation in the experience economy (e.g., Sundbo and Sørensen, 2013; Sundbo, Sørensen and Fuglsang, 2008). In this book we aim to investigate and understand the present status of these, until now separated research fields, and provide more integrative and holistic approaches to service and experience innovation. We have come to a crossroads in innovation. The crossroads means that manufacturing, service, experiences and even primary sectors (agriculture, fishing, mining, forestry etc.) are now integrated when it comes to innovation. Thus, for example, it is necessary to innovate across the whole value chain, or within multi-agent frameworks, and in different complementary ways, or more generally at a system level when innovating a service offering or good. It is thus important to consider innovation as a change involving several economic sectors and several types of innovation processes across sectors. The theoretical understanding must therefore also be all-inclusive and systemic, so the starting point for this book is shown in Figure 1.1: how can integrative perspectives be developed based on research from these areas?

The research conducted in this book points to the following answer to the question above: overall, these three research fields are still separated;

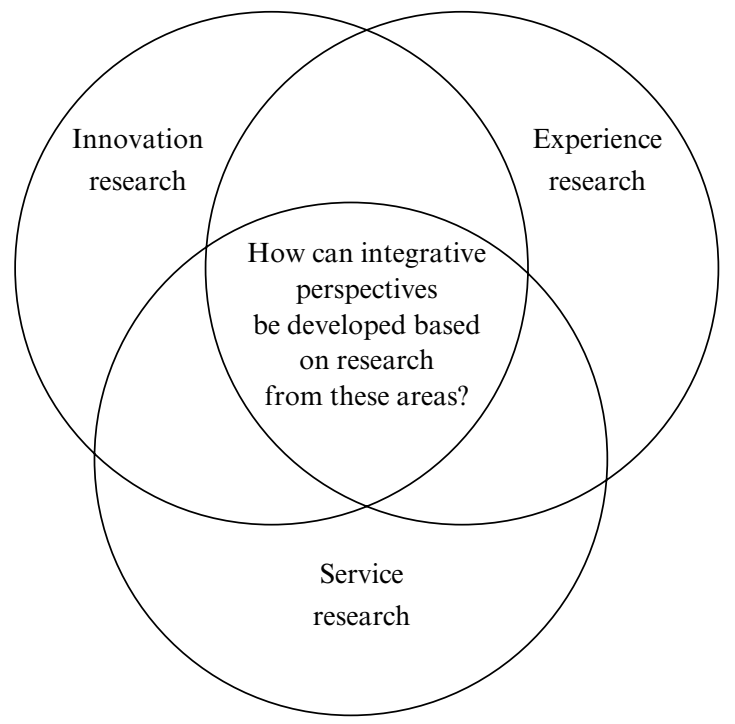

Figure 1.1 Integrative perspectives in research on innovation, service and experience 


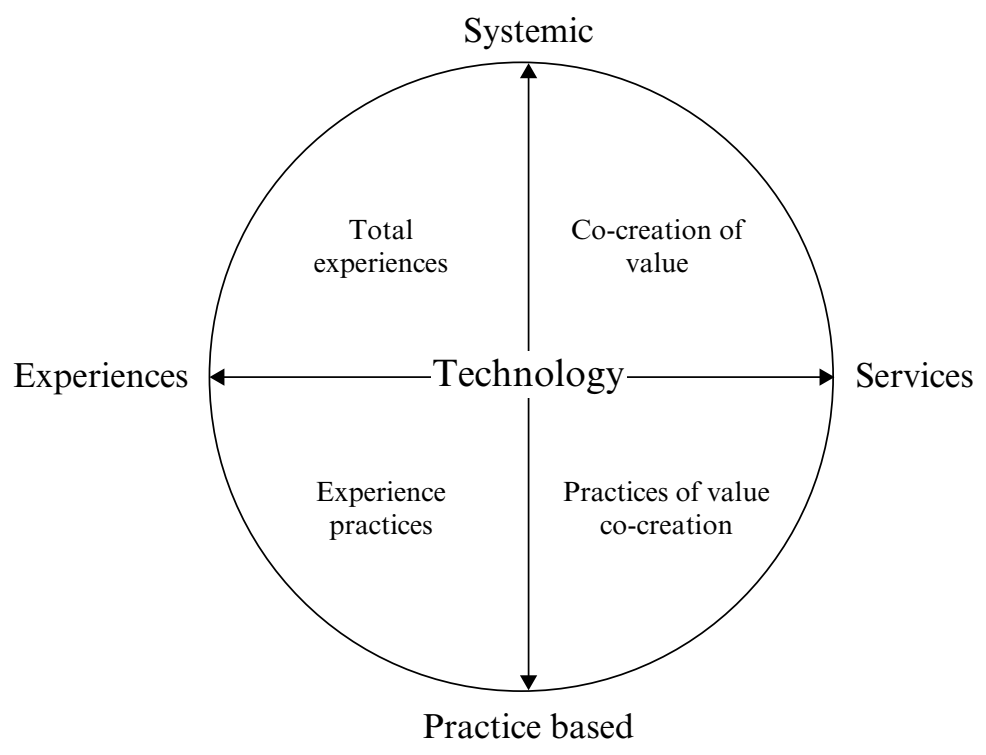

Figure 1.2 A model of integration of service, experience and innovation research

however, several studies are emerging at the boundaries between them or establishing linkages among them (see, for example, Chapter 2 by Rubalcaba in this book). As the model in Figure 1.2 shows, experience and experience industries can be seen as a continuum in relation to service and service industries. At the same time, it is possible to outline two types of integrative perspectives on services and experiences, one that is systemic and one that is practice based. The first follows from the basic idea that innovation is an interactive process with many actors. The second argues for a unit of analysis called practices - that is, the wider historical conditions of experiences and value creation in order to grasp the complexity of innovation. Furthermore, technological transformation is an important motor of innovation and change in all perspectives, as shown in Figure 1.2. We will explain these perspectives in more detail below.

\section{SYSTEMIC INNOVATION}

The book starts from the assumption that integrative and systemic perspectives on innovation in services and experiences research are needed. In policy as well as in research, there may be a tendency to overemphasize 
the role of single factors for innovation such as entrepreneurs, R\&D activities, employees, or management. Simultaneously, there can be a tendency to distinguish services and experiences from each other and from other sectors. Such approaches have been needed in policy and in research to sort out the many facets and specificities that characterize innovation in different sectors and areas. However, research has also demonstrated that innovation is in reality a collaborative and collective process where many mutually contingent factors interact across sectors, types of actors and organizations (Fuglsang and Sundbo, 2005; Lundvall, 1988). The ability to state such a more complex model in theory and in practice may be important for adopting less naive and more economically and socially fulfilling approaches to innovation. It can also broaden the scope of innovation in terms of our understanding of who can contribute, and how. One important way to conceptualize innovation as an interactive, multiple and complex approach is by framing innovation as a systemic activity. Systemic means that innovation is seen as interactive, while also being directed towards certain overall goals that different actors contribute to. There are, however, several ways to conceptualize a systemic approach. The tradition used here is the understanding of system as an ecological system, or ecosystem, in which many factors mutually impact each other in a complex way. This is opposed to a more mechanical or cybernetic understanding of system (Stacey, 2011) as a linear sequence of events.

In service research, an interactive and systemic approach to innovation has been stressed (see Toivonen, Chapter 4, this volume). Compared to manufacturing, service innovations seem softer and more related to human behaviour than to R\&D, and more difficult to plan and disentangle from other activities (Rubalcaba et al., 2012; Sundbo, 1997). The outcome and quality of services can be blurred since innovations can be concealed in coproduction and co-creation activities with end users and other stakeholders in 'the moment of truth' (Normann, 1983). Service innovations can also be hidden in everyday work when employees start to change behaviour independent of management (Fuglsang and Sørensen, 2011). Moreover, service innovations rely on developments in technology and manufactured goods. As stated in the research by Jon Sundbo, actors can be seen as loosely coupled (Sundbo and Gallouj, 2000). This implies, among others, that many things can happen, and many factors influence each other in unpredictable and chaotic ways (Fuglsang and Sundbo, 2005). However, this rather chaotic situation has also led to the recognition of the need for a management system and linearization of service innovation (see Djellal and Gallouj, Chapter 3 in this volume). Nevertheless, as stated by Jon Sundbo (Sundbo and Fuglsang, 2002), the plans and strategies emerging from the management systems have to be reflected in employees' and users' 
activities in order to work. The service approach thus leads towards a dual approach, recognizing both the chaotic, multiple, collaborative, systemic character of service innovation and the need for linearity, planning and strategizing in firms and society.

In the more recent research area of experiences, the second topic of the present book, the key issue is how social and economic activities can trigger memorable experiences (Sundbo and Sørensen, 2013). The value of services and other economic activities is conceptualized as memorable experiences. People have memorable experiences independently of economic activities, but memorable experiences can also be triggered by goods and services that intend to do so. Here too, two simultaneous ontologies are needed to understand and manage experience innovation. On the one hand, experiences of services may be understood as planned by involved actors - both service providers and customers. Coffee is delivered in a planned way by experience providers and customers expect and plan the coffee to provide a special experience. One the other hand, experiences do not happen in isolation but are integrated into what has been called total experiences (Eide, Fuglsang and Sundbo, 2017). Total experiences also rely on services and goods that are normally not experience oriented such as transportation or accommodation. Such experiences are also dependent on the mood and skills of the user. While interdependent actors may work towards the same general goals, they are also very different, have different skills and moods and the outcome of innovations can be unpredictable, multiple and chaotic. Thus, systemic, integrative approaches are greatly needed to understand and engage with the complex and multiple reality of experiences and experience innovation.

To summarize, the complex realities of services, experiences and innovations can be understood through a systemic approach. Innovation can be seen as a loosely coupled interactive process between interdependent economic actors that share an overall common goal. Within a systemic and interactive ontology, it is also clear that actors have intentions, plans and strategies, which they seek to implement through interaction with others. A system can be understood in different ways as ecological and mechanical. The preferred metaphor in service innovation research is often an ecosystem. However, in innovation research, the system metaphor may sometimes have a double connotation of chaotic multiplicity and a planned system. This double ontology is an important explanatory framework in Jon Sundbo's work.

However, the systemic approach also has limitations. Among others, it has little to say about how ecologies of innovation and interaction in a human-centred system are linked to practices - that is, that the actors in an ecosystem develop habitual behaviour in which their experiences, 
emotions, understandings and goals are entangled. A systemic approach focuses on co-creation and total experiences rather than the habitual practice of co-creation and the practices of experiencing - and how innovation can emerge from such practices.

\section{PRACTICE-BASED INNOVATION}

Viewing innovation as emerging from practice - that is, from everyday actions related to social worlds (Feldman and Orlikowski, 2011) - has some similarities with the systemic approach as briefly outlined above, because the practice-based approach also views practices as intertwined in ecologies of interaction. However, the practice-based approach pays more attention to how innovation emerges from everyday action related to work and consumer practices and the experiences, emotions, understandings and goals of actors in a human-centric system. This view of innovation may be particularly relevant to service firms that are seldom R\&D based and often develop innovations from employees' and customers' experiences and practices. Practices are habitual behaviours in which actors are entangled and that they further develop - like when cooking and developing a meal. Such practices are difficult to control and linearize from a management perspective. Yet, recognizing the practice-based character of innovation may enable service managers to engage with and further develop innovative activities present in an organization (cf. Fuglsang, Chapter 8, this volume). Further, collaborating practices are seen as decentred activities that is, they are not necessarily oriented towards the same goal (as is often presumed in a systemic view), rather, they are seen to pursue different and even changing goals in a decentred manner (cf. Bærenholdt, Chapter 7, this volume).

Practices are collective, shared ways of doing and knowing in social and historical contexts that constrain and enable action. While there is no consensus about how to define practices, it is clear that they represent systems of activities or organized sets of actions (Nicolini and Monteiro, 2017) that structure individual behaviour. One definition of practice much quoted in the literature sees practices as 'organized nexuses of actions', consisting of '(1) practical understandings, (2) rules, (3) a teleoaffective structure, and (4) general understandings' (Schatzki, 2002, p. 77). This implies that practices are structures of doing and knowing in relation to some kind of purpose. Practice-based research is not simply focusing on what people do but also on the historical and material conditions for certain activities (Nicolini and Monteiro, 2017). Further, practices are interrelated with other practices they collide with or cohere to. It 
is through practices that certain phenomena, such as services, become enacted. However, a particular service, such as a tourism service, may be enacted in different ways by actors that belong to different practices. In some conceptualizations of practice-based theory, such as actor-network theory, the concept of multiplicity has been stressed (Jørgensen, 2017; Law and Singleton, 2005; Mol, 1999), implying that social phenomena can be enacted in several different ways. The point made is not that a service can be enacted in an unlimited number of ways, yet there is a space of action within which a service can be enacted through practice. Innovations can arise from actors exploring this space of action. Practice-based theory differs from the systemic approach by being very specific about the unit of analysis - namely practice. Practice-based theory has the potential to form the basis of an integrative approach to service and experience innovations by positing this unit of analysis - which is common to all sectors - and by demonstrating the complex intertwinement of practices across sectors.

Thus, a practice-based perspective becomes a corrective to the more linearized versions of innovation processes in some innovation theories (Alam and Perry, 2002) and the more mechanistic uses of systems theory that are widely spread in the literature (Stacey, 2011). Further, it presents a more specific unit of analysis than in the more generalized ecosystemic approaches. In terms of innovation theory, the practice-based perspectives contribute at least the following insights: first, practice-based theorizing becomes a way to capture and uncover how service innovations are embedded in everyday actions and routines - for example, how working, learning and innovation are intertwined phenomena (Brown and Duguid, 1991). This allows researchers to capture types of innovations that are otherwise invisible and unrecognized in research. It has proven useful in service innovation research to observe how innovations can be hidden in everyday activities and consequently can be further strengthened in relation to management and strategy (Fuglsang and Sørensen, 2011). Second, practice-based theorizing becomes a way to recognize the intertwining of innovation activities - that is, how changing elements of one practice affect the other practice. This can lead researchers to study the tensions and conflicts that can emerge from this. There is surprisingly little innovation theory that focuses on conflict, and how conflicts and challenges of practices lead actors collectively to adjust a strategic field of action (Laamanen and Skålén, 2015). Third, practice-based theorizing may lead to more methodological focus on multiplicity. Often, during case studies, it may be difficult to keep the initial focus because of continuous changes in the field (Law and Singleton, 2005). An activity, such as a service, seems to be enacted in many different ways and it changes continuously. Thus, making the ontological stance of multiplicity may be one way to deal 
with this methodological challenge and to engage with the complexity of action (Jørgensen, 2017). Finally, practice-based theorizing also fulfils a need to explore in detail the types of sub-practices involved in innovation activity (Fuglsang, Chapter 8 , this volume). Rather than focusing on roles or systems of innovation, a focus on practices will allow the researcher to recognize the social structures of innovation in terms of organized sets of action.

Jon Sundbo's work contains many practice-oriented ideas that could be interpreted as a practice-based perspective. One example is the concept of strategic reflexivity positing that strategies have to be reflected in employees' behaviours (Fuglsang and Sundbo, 2005). Thus, strategy is something practised or related to practices. In Sundbo's work, the concept of innovation strategy is important, but not only as a phenomenon that can be designed by managers. Strategy can also be something that emerges from practices and is then strengthened through management activities.

\section{INFORMATION AND COMMUNICATION TECHNOLOGIES AS INNOVATION MOTOR}

Over the last decades there has been an increasing focus on ICTs as a transformational force in services and service innovations across different socioeconomic sectors (Barrett et al., 2015). Technology, and especially ICTs, have been historically a primus motor for service innovation either by enabling the creation of entirely new types of services (such as, for example, satellite services as described by Billing and Bryson in Chapter 12 of this book) or by digitalizing some parts of the service offering, such as, for example, in some library services (e.g., Barras, 1986; Barrett et al., 2015; Scupola, 2009).

Traditionally, ICTs have been conceptualized as technological tools that may change the service delivery process, thus contributing to improved productivity and efficiency of service firms and may lead to entirely new markets or types of services (Barras, 1986; Barrett et al., 2015). The services (or part of the services) enabled by ICTs have been conceptualized in the literature in different ways, such as, for example, e-services, digital services, ICT-based services or self-services (e.g., Scupola et al., 2009). However, besides being the major motor for service innovation and transformation, ICTs have also been conceptualized to take other roles in service innovation. Lusch and Vargo (2014), for example, by arguing that all economic activities can be conceptualized as service exchanges, consider ICT as a key resource together with other resources such as skills and knowledge in service innovation (Barrett et al., 2015). 
In addition, ICT is becoming a central infrastructure or platform for service and experience delivery and innovation (e.g., Pine and Gilmore, 2017; Strøm and Ernkvist, Chapter 18 in this book), as, for instance, many services such as e-banking, navigation services or online games cannot be provided without the underlying hardware. The boundaries between the hardware (the product enabling the service) and the service itself become very blurred, thus giving rise to what has been called in the literature 'service encapsulation' (Howells, 2010). The chapter written by Uljala and Scupola in this book (Chapter 11) shows, for example, how a new type of service intertwined with the underlying software and hardware infrastructure (e-residency) is generating new global entrepreneurship. In addition, Chapter 12 by Billing and Bryson provides examples of how digital infrastructures enable new services such as satellite services that contribute to economic growth. Barrett et al. (2015) pointed out how recent work on digital infrastructure has also highlighted the generative nature of digital technologies (Henfridsson and Bygstad, 2013), which may also facilitate service innovation (Yoo et al., 2012). An example of the generative nature of digital technologies is provided by Henten and Sørensen in Chapter 13 of this book. They show, in fact, how the digitalization of services is making it possible to collect a huge quantity of data on customer behaviour, thus making it potentially easier to innovate the services and service offerings or even to generate new services 'on the fly' on the basis of digitally recorded customer behaviour.

\section{STRUCTURE OF THE BOOK}

To address the purpose of the book and especially the interlinkage among these different research fields and perspectives, the book chapters present different aspects and views of an integrated approach to innovation in service and experience research. They do it in different ways. Some chapters deal with service innovation, others mainly focus on the experience aspects, while some bridge different aspects of experience and innovation research. The chapters have been organized into four parts, each one constituting a pillar toward the holistic understanding of this phenomenon. Finally, the contributions are both theoretical, thus pushing the theoretical boundaries of these research fields, and empirical, thus showing how these research fields evolve in practice. Still others present a combination of theoretical discussion with empirical investigations and illustrations. 


\section{Part I: Systemic Innovation}

This part includes five chapters. Chapter 2 by Luis Rubalcaba provides a theory about integrating service experiences with service innovations. By arguing that service encounters lie at the core of this integration, the chapter illustrates the nature of service innovation in the light of service experiences in terms of connecting and engaging people. The main hypothesis of the chapter is that the social context is a major factor bridging service experience and service innovation, thus reinforcing the bridge between service innovations and social innovations.

Chapter 3, written by Faridah Djellal and Faïz Gallouj, conducts a survey of surveys on the relatively young field of service innovation studies (SIS) with the objective to compile a list of what they consider the 15 major advances made in the SIS field since its advent. They divide these advances into two groups. The first group reflects changes in recognition of SIS and understanding of the fundamental nature of service innovation. The second encompasses advances in innovation modes and advances in institutional and regulation arrangements. The chapter concludes with a number of challenges for future research in SIS.

Chapter 4 by Marja Toivonen discusses four central perspectives to service innovation: managing innovation processes, taking a strategic stance to innovation, promoting user-based and employee-driven innovation, and answering the need for systemic innovations. The chapter shows that Jon Sundbo has contributed in a notable way to research in all these areas. For example, he has introduced the idea of 'balanced empowerment' to emphasize the importance of strategy in the inducement and control of innovation activities. He has developed the framework of strategic reflexivity, focusing on top-down processes that integrate distributed novelties, while supplementing the picture by analysing the bottom-up processes in which grassroots employees transmit users' ideas into the organization - what Sundbo calls customer encounter-based innovation. The concept of 'after innovation' emphasizes the active role of users also after the innovation launch. Finally, Marja Toivonen shows how Sundbo has participated in the broader societal-level discussion about value chain innovations.

Chapter 5 written by Metka Stare and Dejan Križaj focuses on research and development methods, addressing interconnected products, services and experiences of particular relevance in tourism. The chapter aims at scrutinizing innovations in tourism, focusing on recently awarded innovations by the national innovation-supporting mechanism recognized by international institutions. One of the recently proposed approaches relates innovation and experience design aspects to touch points (Experiences through Design, Innovation and Touch points - EDIT). The chapter 
applies case study analysis to evaluate the applicability of the EDIT model for a more holistic understanding of the new realities at the innovation crossroad' - the contingency that this book is targeting. The results of analysis provide deep insight into the innovation process in tourism from the perspective of theoretical advancement and policy design.

In Chapter 6, Matthijs J. Janssen and Pim den Hertog argue that service innovation is increasingly recognized as the (re)design of multidimensional and complex systems and that complex systems theory in the form of NK-models, based on an evolutionary interpretation of innovation, may be a promising theoretical perspective. They apply the NK-logic in the context of services to explore eight qualitatively studied service innovations by mapping each of them on one multidimensional conceptualization, thus advancing the multidimensional approach to service innovation. The chapter argues that familiarity with common dimensions might provide valuable guidance to service innovators.

\section{Part II: Practice-based Innovation}

This part, comprising four chapters, emphasizes practice as a unit of analysis in the integrated innovation approaches highlighted above. In Chapter 7, Jørgen Ole Bærenholdt argues that the practices involved in making new tourist destinations in the experience economy are often about the mobilization of multiple actors across sectors, agendas and places. To show this, the chapter investigates the making of the new Camøno hiking route on the Danish island of Møn during 2016. The route was gradually established through networking among architects, tourism developers, the local museum, local entrepreneurs, municipal planners and the Realdania foundation. Inspired by actor-network theory methodology and based on interviews with involved actors and participant observation in workshops and evaluation meetings, the study describes the processes of making the hiking route. The analysis reveals decentred innovation practices dealing with material objects and fragile practices, stabilized through a strong narrative around the name of the Camøno route.

Chapter 8, written by Lars Fuglsang, starts from practice-based research on innovation to develop a framework of service innovation by integrating the concept of 'relationality' into the practice-based approach and specifying sub-practices of service innovation. The proposed framework extends previous approaches to practice-based research on service innovation by seeking to explain more effectively how service innovations progressively become engaged and stabilized in collective structures - thereby moving the focus of service innovation research from creativity to stabilization. The chapter outlines three relational sub-practices that describe different 
degrees of engagement of service relations into the environment: the bricolage approach, the system-oriented approach and the systemic approach. In two case vignettes, the chapter illustrates the framework and discusses implications for research and management.

In Chapter 9, Niels Nolsøe Grünbaum and Marianne Stenger argue that new product development (NPD) and new service development (NSD) have been criticized in relation to their adaptability to radical innovation, even though there is consensus in the literature that they are crucial for companies' ability to survive and deliver value and profit for their shareholders. More specifically, the authors argue that there is a lack of recommendation to managers on how present NPD and NSD models should help manoeuvring in high-risk situations. They address this issue by embracing intuition as a dynamic capability in decision-making to supplement the classical cognitive perspective and contribute to the understanding of the managerial 'black box' addressed in the strategic management literature. The chapter makes two contributions. First, an understanding of intuition components and their link to the development of products and services is offered. Second, it is argued that the proposed intuition NPD and NSD framework can potentially improve the information-gathering system, which may lead to better decision-making.

Chapter 10, written by Jørn Kjølseth Møller, examines and discusses the impact of 'servitization' and 'service infusion' in manufacturing companies by contextual analysis of previous studies in the development of different service logics and a case study of the wind turbine industry (use of service agreements). The aim is to answer the following questions: What is changed by the increased service infusion of a manufacturing company and in the relationship between providers and customers? Why are service offerings and service components increasingly becoming an essential part of the business model and innovation process of sophisticated products, creating a solutions market with different corporate strategies? How do manufacturing companies decide to organize ('internally' or 'externally') their solution offerings depending on the impact from several factors?

\section{Part III: Technology and Service Innovation}

The third part includes four chapters presenting different roles that digital technologies and tools take on in service innovations and growth.

Chapter 11 by Linda Uljala and Ada Scupola investigates one of the recent e-service innovations influencing entrepreneurial practices in the global sphere, namely Estonian e-Residency. E-Residency is an example of a service where the boundaries between the hardware (the product enabling the service) and the service itself become very blurred, thus giving rise to 
what has been called in the literature 'service encapsulation'. Given its newness, this study investigates the motivators and inhibitors of Estonian e-Residency adoption for global e-entrepreneurship. The theory of diffusion of innovations is applied to conduct a qualitative investigation from the e-entrepreneur's perspective. Findings show that a number of factors characterize the e-Residency adoption process and that such a process might be more complicated than what is expected at first glance.

In Chapter 12, Chloe A. Billing and John R. Bryson explore the structure of the UK space industry, highlighting the interdependencies between manufacturing and service functions and the emergence of hybrid products and production processes. The UK satellite industry consists of three sub-sectors: the manufacture of satellites, operation of satellites and providers of satellite-enabled services. The chapter highlights the importance of exploring the interdependencies between manufacturing and service functions and suggests that research should shift the focus of attention away from manufacturing or services to a focus on understanding the creation of value through the provision and consumption of service-enabled experiences.

Chapter 13, written by Anders Henten and Jannick Kirk Sørensen, investigates the research question of how digital service encounters differ from face-to-face (f2f) encounters in terms of potential innovative generativity. The authors argue that new computer technologies such as big data processing, recommender systems and developments in artificial intelligence will enhance the potential for innovations to be created on the basis of digital service encounters. However, they argue that the empathetic understanding of the needs and wants of the service users that may be part of the f2f service encounters cannot automatically be generated from digital service encounters. Therefore, digital tools can be developed and used to supplement the impressions that $\mathrm{f} 2 \mathrm{f}$ encounters initiate.

Giulia Nardelli and Ada Scupola in Chapter 14 investigate and conceptualize user involvement in business-to-business service innovations as well as the tools that are used to support interactions in such a complex process. The chapter is built on a qualitative research study in a specific type of business-to-business operational service - facility management service. The results indicate that, in this business-to-business context, the involvement of users is variable depending on the offered services as well as on the specific role that users play with regard to the service being innovated. This is due to the different needs and expectations of users with respect to the service innovation in question. 


\section{Part IV: Experience as Innovation Motor}

The fourth and last part includes four chapters dealing with different aspects and sectors of the experience economy. Chapter 15 by Jens Friis Jensen and Flemming Sørensen discusses how front-line employees can play an important role in innovation processes that lead tourism companies from a focus on standardized service production to experience value creation. Following the book's main theme of integration, the chapter contributes to the understanding of the role that front-line employees can have in innovation processes taking place at the crossroads of service and experience. In services in general, front-line employees can be important in bottom-up unorganized and bricolage-based innovation processes as well as in more systematized innovation processes. This potential also exists in tourism companies; however, in these companies, which are often hierarchically organized, front-line employees are mostly not considered important innovation agents.

In Chapter 16, Ian Miles, Ming-Fei Lee and Kantima Sawatwarakul argue that coffee shops are rich in experience, even if their explicit function seems to be the provision of consumables, and investigate coffee shops in two East Asian countries (Thailand and Taiwan). The findings show much innovative effort underway, centred not only on the food and beverages supplied, but also on other elements shaping consumer experience - such as decor, location of activities and arrangement of devices, and staff roles. The study finds high levels of innovation, of many forms, in both large chains and smaller traditional shops. The authors argue that many experience industries are also likely to display substantial innovation, therefore researchers should look beyond the narrow categories that have been the focus of most innovation studies so far.

Paolo Corvo and Raffaele Matacena in Chapter 17 present 'Cortilia' and 'L'Alveare che dice Sì!', two rapidly consolidating business-oriented alternative food-provisioning models from the city of Milan. The authors argue in fact that the chain of food production, distribution and consumption is undergoing an intense process of innovation. This is due to new and varied models of food provisioning emerging in Western cities, in which food is produced, sold and distributed in the light of three basic principles: the chain is as short as possible; the food is of higher quality and environmental values; and a direct relation between producers and consumers is built and sustained. These models are known as 'alternative' or local food networks and are run and operated by an original alliance of collective and individual stakeholders. They use the Internet and digital technologies as the stepping stone of their organization and, interestingly, exercise their activities (at least partly) outside the mechanisms and infrastructure of the corporate-controlled dominant food distribution sector. 
Patrik Ström and Mirko Ernkvist in Chapter 18 study the development and internationalization of the Korean online game industry. This industry has become an important part of the cultural and creative industry in Asia and has had particular success in Korea. The interconnectedness of the services and goods production is vital to understand the overall development of this industry. The study shows how the specific industry framework and its national support in Korea facilitated the transcultural circulation and geographical development within the industry. Finally, the study demonstrates the complexity that exists when firms, often characterized as online service providers (OSPs), enter the international market.

\section{CONCLUSIONS}

This introductory chapter to this book, Services, Experiences and Innovation: Integrating and Extending Research, has argued for the importance of the volume by addressing the overall research question of 'How can integrative perspectives be developed based on innovation, service and experience research?'

The chapter has argued that we have come to a crossroads in these, until now separated research fields, and it is necessary to find more holistic, integrative and systemic approaches to these fields of research. To address this gap, the chapter has developed a model (Figure 1.2), arguing for research on services and experiences as arranged in a continuum (horizontal axis), wherein much innovation has been seen and is still seen as driven by developments in the field of ICTs (Barrett et al., 2015). ICTs can be conceptualized as having different roles in experience and services innovation, such as, for example, the platform role. In addition, the model identifies two innovation approaches - the practice-based approach and the systemic approach - and mixtures between them in a continuum that in varying degrees may be useful to explain and understand the type of innovation taking place in the service and experience fields. Based on the four variables (systemic vs practice-based innovation and service vs experience) of these two axes, the model then identifies four areas at the crossroads of innovation, service and experience research that deserve further attention and theorizing in future research: total experiences vs experience practices and co-creation of value vs practices of value co-creation.

Each of the four parts of the book aims at addressing, more or less explicitly, some aspects of the theoretical model of Figure 1.2. The 18 chapters of the book reveal that, overall, these three research fields of service, innovation and experience research are still separated; however, 
several chapters also show that integration among these three different fields is emerging and that there is great potential for future research as, for example, is shown in the chapters by Rubalcaba (Chapter 2) and Miles et al. (Chapter 16). We argue that future research should build on this book's seminal model and work, thus continuing and further developing the research at the crossroads of service, innovation and experience research, the ground set by Professor Jon Sundbo.

\section{REFERENCES}

Alam, I. and C. Perry (2002), 'A customer-oriented new service development process', Journal of Services Marketing, 16(6), 515-34.

Baines T., H. Lightfoot, O. Benedettini and J. Kay (2009), 'The servitization of manufacturing', Journal of Manufacturing Technology Management, 20(5), 547-67.

Barras, R. (1986), 'Towards a theory of innovation in services', Research Policy, 15(4), 161-17.

Barrett, M., E. Davidson, J. Prabhu and S.L. Vargo (2015), 'Service innovation in the digital age', MIS Quarterly, 39, 135-54.

Brown, J.S. and P. Duguid (1991), 'Organizational learning and communitiesof-practice: Toward a unified view of working, learning, and innovation', Organization Science, 2(1), 40-57.

Eide, D., L. Fuglsang and J. Sundbo (2017), 'Management challenges with the maintenance of tourism experience concept innovations: Toward a new research agenda', Tourism Management, 63, 452-63.

Feldman, M.S. and W.J. Orlikowski (2011), 'Theorizing practice and practicing theory', Organization Science, 22(5), 1240-53.

Fuglsang, L. and F. Sørensen (2011), 'The balance between bricolage and innovation: Management dilemmas in sustainable public innovation', Service Industries Journal, 31(4), 581-95.

Fuglsang, L. and J. Sundbo (2005), 'The organizational innovation system: Three modes', Journal of Change Management, 5(3), 329-44.

Gallouj, F. and O. Weinstein (1997), 'Innovation in services', Research Policy, 26, 537-56.

Henfridsson, O. and B. Bygstad (2013), 'The generative mechanisms of digital infrastructure evolution', MIS Quarterly, 37(3), 907-31.

Howells, J. (2010), 'Innovation, consumption and services: Encapsulation and the combinatorial role of services', The Service Industries Journal, 24(1), 19-36.

Jørgensen, M.T. (2017), 'Reframing tourism distribution - activity theory and actor-network theory', Tourism Management, 62, 312-21.

Laamanen, M. and P. Skålén (2015), 'Collective-conflictual value co-creation: A strategic action field approach', Marketing Theory, 15(3), 381-400.

Law, J. and V. Singleton (2005), 'Object lessons', Organization, 12(3), 331-55.

Lundvall, B.-A. (1988), 'Innovation as an interactive process: From user-producer interaction to the national system of innovation', in G. Dosi, C. Freeman and R. Nelson et al. (eds), Technical Change and Economic Theory, London: Pinter, pp. 349-69. 
Lusch, R.F. and S.L. Vargo (2014), Service-Dominant Logic: Premises, Perspectives, Possibilities, Cambridge, UK: Cambridge University Press.

Mol, A. (1999), 'Ontological politics. A word and some questions', in J. Law and J. Hassard (eds), Actor-Network Theory and After, Oxford: Blackwell.

Nicolini, D. and P. Monteiro (2017), 'The practice approach: For a praxeology of organisational and management studies', in A. Langley and H. Tsoukas (eds), The SAGE Handbook on Organizational Studies, London: SAGE, pp. 110-26.

Normann, R. (1983), Service Management, New York: Wiley.

Pine, J. and J. Gilmore (1998), 'Welcome to the experience economy', Harvard Business Review, 76(4), 97-105.

Pine, J. and J. Gilmore (1999), The Experience Economy, Boston, MA: Harvard Business School Press.

Pine, J. and J. Gilmore (2017), 'Distinctive experiences', Journal of Shopper Research, 1(1), 60-65.

Rubalcaba, L., S. Michel and J. Sundbo et al. (2012), 'Shaping, organizing, and rethinking service innovation: A multidimensional framework', Journal of Service Management, 23(5), 696-715.

Schatzki, T.R. (2002), The Site of the Social: A Philosophical Account of the Constitution of Social Life and Change, University Park, PA: Pennsylvania State University Press.

Scupola, A. (ed.) (2009), 'E-services in Danish research libraries: Issues and challenges at Roskilde University library', in Cases on Managing E-services, Hershey, PA: Idea Group Inc., pp. 204-17.

Scupola, A., A. Henten and H. Nicolajsen (2009), 'E-services: Characteristics, scope and conceptual strengths', International Journal of E-Services and Mobile Applications, 1(3), 1-16.

Stacey, R.D. (2011), Strategic Management and Organizational Dynamics: The Challenge of Complexity, 6th edition, Harlow: Prentice Hall.

Sundbo, J. (1997), 'Management of innovation in services', Service Industries Journal, 17(3), 432-55.

Sundbo, J. (2000), 'Organization and innovation strategy in services', in M. Boden and I. Miles (eds), Services and the Knowledge-Based Economy, London and New York: Continuum, pp. 109-28.

Sundbo, J. and L. Fuglsang (eds) (2002), Innovation as Strategic Reflexivity, London: Routledge.

Sundbo, J. and F. Gallouj (2000), 'Innovation as loosely coupled system in services', in J.S. Metcalfe and I. Miles (eds), Innovation Systems in the Service Economy: Measurement and Case Study Analysis, London: Kluwer, pp.43-68.

Sundbo, J. and F. Sørensen (eds) (2013), 'Introduction to the experience economy', in Handbook on the Experience Economy, Cheltenham, UK and Northampton, MA, USA: Edward Elgar Publishing, pp. 1-17.

Sundbo, J., F. Sørensen and L. Fuglsang (2008), 'Innovation in the experience sector', paper presented at the RESER conference, Stuttgart, Germany.

Sundbo, J., D. Sundbo and A. Henten (2015), 'Service co-innovation: Service encounters as basis for innovation', The Service Industries Journal, 35(5), 255-74.

Yoo, Y., R.J. Boland, K. Lyytinen and A. Majchrzak (2012), 'Organizing for innovation in the digitized world', Organization Science, 23(5), 1398-1408. 